\title{
A dental microwear texture analysis of the Mio-Pliocene hyaenids from Langebaanweg, South Africa
}

\author{
Deano D. Stynder, Peter S. Ungar, Jessica R. Scott, and Blaine W. Schubert \\ Acta Palaeontologica Polonica 57 (3), 2012: 485-496 doi: http://dx.doi.org/10.4202/app.2011.0053
}

Hyaenids reached their peak diversity during the Mio-Pliocene, when an array of carnivorous species emerged alongside dwindling civet-like and mongoose-like insectivorous/omnivorous taxa. Significantly, bone-cracking morphological adaptations were poorly developed in these newly-emerged species. This, their general canid-like morphology, and the absence/rarity of canids in Eurasia and Africa at the time, has led researchers to hypothesise that these carnivorous Mio-Pliocene hyaenas were ecological vicars to modern canids. To shed further light on their diets and foraging strategies, we examine and compare the dental microwear textures of Hyaenictitherium namaquensis, Ikelohyaena abronia, Chasmaporthetes australis, and Hyaenictis hendeyi from the South African Mio-Pliocene site of Langebaanweg with those of the extant feliforms Crocuta crocuta, Acinonyx jubatus, and Panthera leo (caniforms are not included because homologous wear facets are not directly comparable between the suborders). Sample sizes for individual fossil species are small, which limits confidence in assessments of variation between the extinct taxa; however, these Mio-Pliocene hyaenas exhibit surface complexity and textural fill volume values that are considerably lower than those exhibited by the living hyaena, Crocuta crocuta. Dental microwear texture analysis thus supports interpretations of craniodental evidence suggesting low bone consumption in carnivorous Mio-Pliocene hyaenas.

Key words: Mammalia,Hyaenidae, durophagy, dental microwear textures, Mio-Pliocene, South Africa.

Deano D. Stynder [Deano.Stynder@uct.ac.za], Department of Archaeology, Faculty of Science, University of Cape Town, Private Bag, Rondebosch 7701, South Africa; Peter S. Ungar [pungar@uark.edu], Department of Anthropology, University of Arkansas, Old Main 330, Fayetteville, AR 72701, USA; Jessica R. Scott [jrs17@uark.edu ], Environmental Dynamics Doctoral Program, University of Arkansas, 113 Ozark Hall, Fayetteville, AR 72701, USA; Blaine W. Schubert [schubert@etsu.edu], Department of Geosciences and Don Sundquist Center of Excellence in Paleontology, Box 70357, East Tennessee State University, Johnson City, TN 37614, USA. 
This is an open-access article distributed under the terms of the Creative Commons Attribution License (for details please see creativecommons.org), which permits unrestricted use, distribution, and reproduction in any medium, provided the original author and source are credited.

Farif Full text $(520.3 \mathrm{kB})$ 